\title{
Acute Epidural Hematoma Following a Cervical Epidural Injection in a Patient without Bleeding Risk
}

\author{
Laxmaiah Manchikanti, MD¹, Thomas J. Gruber, MD¹, Hari Prabhakar, MD², and Joshua A. Hirsch, MD³
}

An acute epidural hematoma following a cervical interlaminar epidural injections is rare, but when it occurs, it can be associated with devastating complications if appropriate corrective action is not taken. Surgical decompression or conservative management has been proposed in managing acute epidural hematoma, based on the progression of symptomatology with neurologic dysfunction.

We report a case of a cervical epidural hematoma in a healthy 43-year-old functioning female patient without overt risk factors for procedural hemorrhagic complications including baseline coagulopathy, baseline dysfunction, and intake of anticoagulants. There were no technical difficulties in performing the procedure. The patient developed symptomatology consisting of neck pain, left upper extremity pain, weakness in the left lower extremity, and inability to urinate following the cervical interlaminar epidural. Unbeknownst to the provider, who had performed the epidural injection, the patient presented to the local emergency room and underwent a workup to rule out cardiac etiologies for her symptoms. The patient was also given ketorolac intravenously for neck pain. The provider who performed the epidural injection was informed 18 hours post-procedure.
The patient had progressive symptomatology with neurological dysfunction including weakness and numbness. The provider suspected an epidural hematoma. As a result, an emergent magnetic resonance imaging (MRI) was performed, which showed a significant collection of blood within the epidural space, which clinically required surgical decompression. Subsequently, surgical decompression was carried out with full recovery of neurologic function.

Issues in managing an acute epidural hematoma are related to avoidance of drugs increasing hemorrhagic complications and rapid diagnosis with appropriate therapy, with shared decision making. These hematomas can be managed conservatively or with surgery. Nonsurgical management is influenced by the initial neurological presentation and spontaneous recovery or at least lack of progression of the deficit. After reasonable monitoring, if stable status is absent and neurological dysfunction is increasing, then surgical decompression is recommended.

Key words: Cervical epidural injection, cervical epidural hematoma, bleeding risk factors, surgical decompression, nonsurgical management, ketorolac
From: 'Pain Management Center of Paducah, Paducah, KY; ${ }^{2}$ Baptist Health, Paducah, KY; ${ }^{3}$ Massachusetts General Hospital and Harvard Medical School, Boston, MA

Author for correspondence: Laxmaiah Manchikanti, MD Address: Pain Management Center of Paducah, 2831 Lone Oak Rd, Paducah, KY 42003

E-mail: drlm@thepainmd.com
Significant literature continues to accumulate for interventional techniques and related hemorrhagic risks in recent years (1-7). An overwhelming majority of the literature has focused on patients receiving antithrombotic or anticoagulant therapy and discussions about optimal duration to discontinue anticoagulants. Cervical epidural injections with or without steroids are 
commonly used in the management of chronic neck pain, secondary to multiple pathologies (8-11) and have been shown to be effective based on the evidence derived from systematic reviews of randomized controlled trials. The analysis of utilization patterns in the United States in the Medicare population for cervical and thoracic epidural procedures demonstrated 397 per 100,000 population in 2016 , with significant increases of $101 \%$ from 2000 to 2009 with an annual increase of $8 \%$, but with reduced growth in utilization with only a $4 \%$ increase (or annual increase of $0.5 \%$ ) from 2009 to 2016. Multiple prospective evaluations have studied the bleeding risk of interventional techniques in chronic pain $(8,12,13)$. In addition, multiple investigations have been performed to assess the risk of cervical epidural injections in chronic pain management settings (14-19). Manchikanti et al, in studying the role of antithrombotics $(15,16)$ and complications of epidural injections by other investigators (14,17-20), have shown a lack of correlation of epidural hematoma formation with cervical epidural injections and anticoagulant therapy. In a manuscript describing prevalence of epidural hematoma following cervical epidural injections, Manchikanti et al (4) described one patient requiring surgical decompression, with a second patient improving without surgical decompression. Both patients had no history of taking anticoagulants. Epidural hematoma formation has also been reported in patients receiving ketorolac, selective serotonin reuptake inhibitors (SSRIs), flaxseed, fish oil, and other herbal products $(1-3,6,14)$. Smith et al (19), in a recent systematic review, concluded that other than interlaminar procedures, the evidence does not support the view that anticoagulant and antiplatelet medication must be ceased before image-guided spine pain procedures. They showed that procedures involving interlaminar access carry a risk of hemorrhagic complications, regardless of whether anticoagulants are ceased or continued. Further, the evidence also showed that ceasing anticoagulants carried a risk of serious thrombotic consequences, including death. Thus, it is clear that epidural hematoma may be associated with or without anticoagulant therapy during interlaminar access.

We report a case of a healthy female patient with previous anterior cervical discectomy and fusion with no hemorrhagic risk factors related to bleeding.

\section{CASE REPORT}

The patient is a 43-year-old caucasian female with a body mass index (BMI) of 20.7. She suffered from chronic pain associated with radiation into shoulder blades and upper back with headaches. The patient was treated with cervical epidural injections after testing negative for facet joint pain, and had been receiving cervical interlaminar epidural injections once every 3 to 6 months for the prior 4 years with local anesthetic alone without steroids, with no adverse effects. Magnetic resonance imaging (MRI) of her cervical spine with and without contrast performed in September 2012 showed a stable anterior cervical fusion with mild reversal of the mid cervical curvature. There was a small right paracentral disc protrusion at C6-C7 with mild narrowing of the canal at C5-C6 related to the posterior osteophyte that barely contacted the cord, with no cord displacement or compression. No abnormal contrast enhancement was identified.

In November 2017, she presented with usual symptoms of returned pain after good relief lasting almost 3 months for a repeat epidural injection. After initial preparation, she was transferred to the operating room with intravenous placement. She was positioned in prone position and sterile preparation was carried out with DuraPrep. Following this, under appropriate sedation, the epidural space was entered between C6 and $\mathrm{C} 7$ with a paramedian approach under posteroanterior fluoroscopy guidance. The needle was placed with loss of resistance technique without difficulty, with intermittent fluoroscopy followed by an injection of Omnipaque 240, $2 \mathrm{~mL}$. This injection showed good filling pattern into the epidural space, without subarachnoid or intravascular entry (Fig. 1). Following this, she was injected with $5 \mathrm{~mL}$ of $0.5 \%$ lidocaine. Total fluoroscopy time was 5 seconds. There were no side effects or complications noted either in the recovery room or at the time of discharge. The procedure was considered uneventful.

The next morning, (18 hours after the procedure), the patient notified the interventional practitioner that she had started experiencing left upper extremity pain with neck pain and some numbness and weakness in the left lower extremity with inability to urinate. She presented to the emergency room at a local hospital 6 hours after the procedure. In the emergency room, 


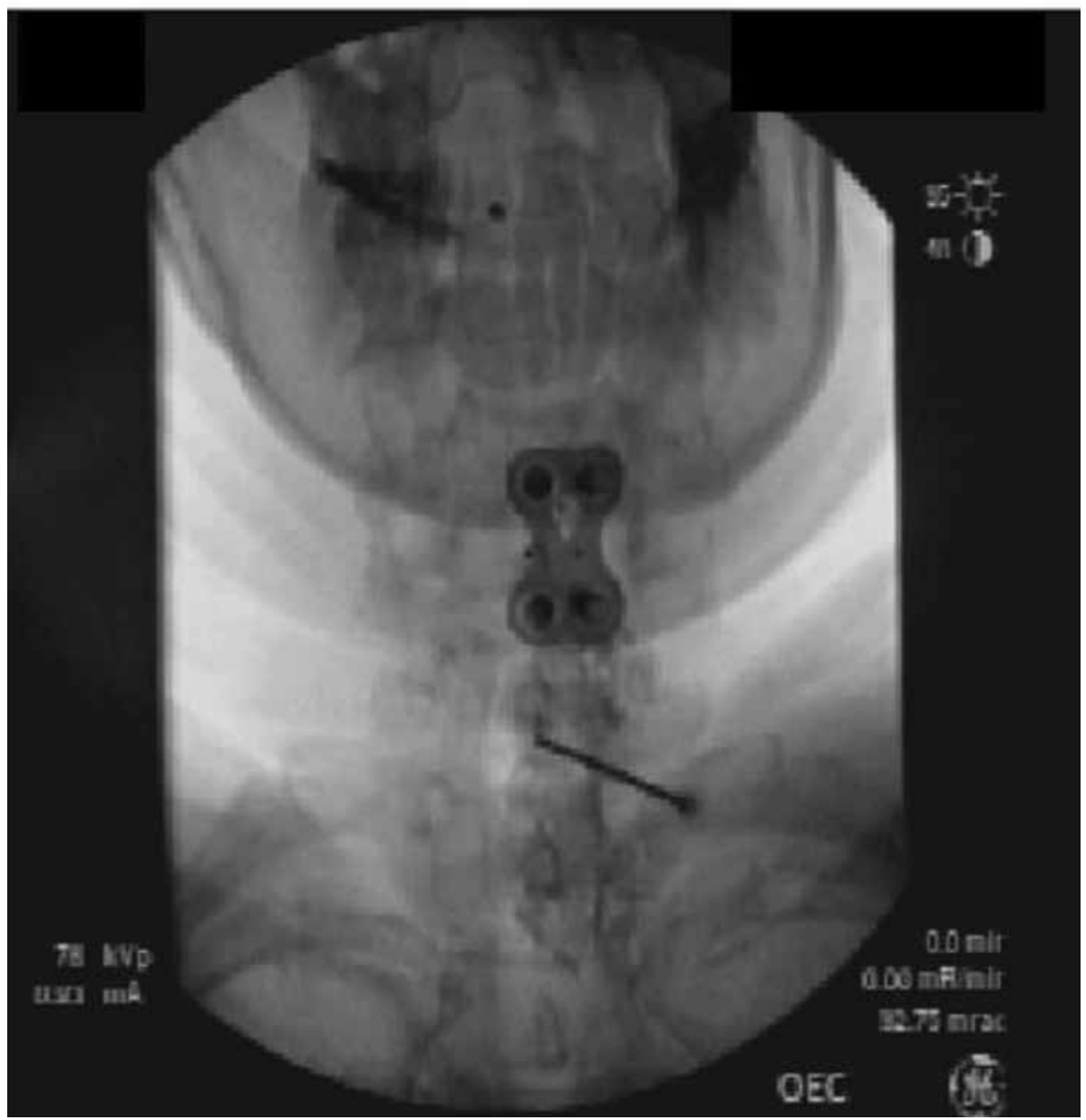

Fig. 1. Cervical interlaminar epidural injection at C6-C7 with contrast injection.

she underwent a cardiac workup to rule out myocardial infarction and was administered intravenous ketorolac. She was also catheterized since her bladder was full and was subsequently discharged with continued symptomatology. She progressively worsened and called the first author (LM) in the morning. An epidural hematoma was suspected and an emergent MRI was ordered. Review of the MRI with the radiologist revealed a $5.4 \times 1.7 \times 0.9 \mathrm{~cm}$ collection of blood within the right dorsal lateral epidural space, spanning from C6-T2 levels. This collection was intrinsically bright on the T1 weight image with a heterogeneously bright appearance on the T2 weighted images and no enhancement. The collection also displaced the cervical cord anteriorly and to the left with complete effacement of the normal cerebrospinal fluid signal. Tiny air bubbles were also detected. Overall, there was severe spinal stenosis, even though there was no definite cord signal abnormality identified. Figures 2 and 3 illustrate the hematoma.

Following the assessment, a neurosurgeon at the initial hospital was consulted. That neurosurgeon opted to manage the patient conservatively. She was extremely anxious with increasing symptomatology, including progressive weakness and numbness. The patient desired to be transferred to a different facility for a second opinion. As a result, she was transferred to the second hospital and the first author (LM) reviewed the MRI with the 


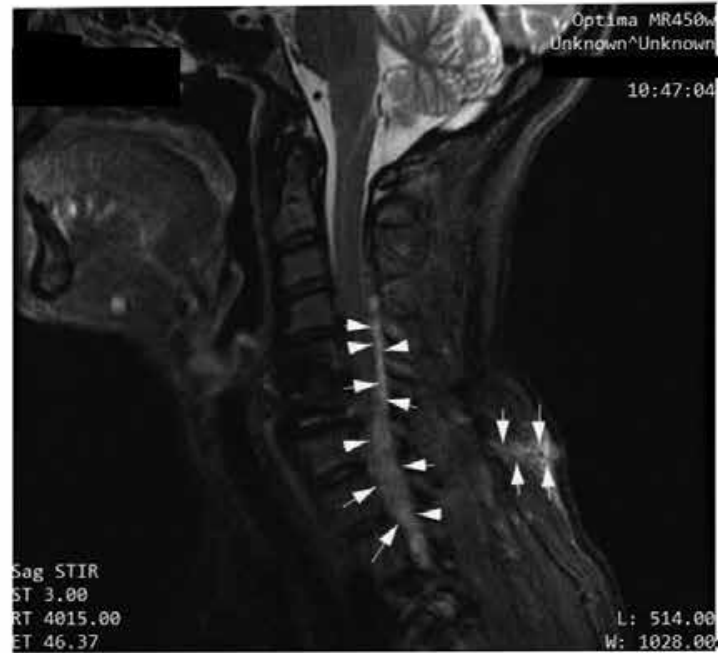

A. MRI Sagittal STIR imaging, demonstrating borders of epidural hematoma (left), and initial tract of injection (right) into the epidural space.

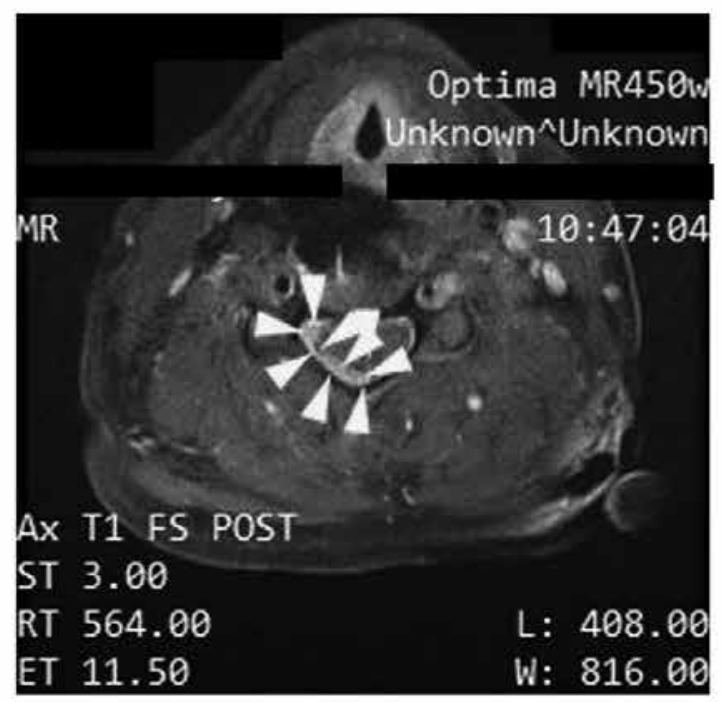

C. MRI Axial T1 FS Post imaging showing borders of epidural hematoma and mild compression of the cord to the left.

Fig. 2. MRI of epidural hematoma.

neurosurgeon (TG). A decision was made to proceed with immediate decompression under general anesthesia. Laminectomies were performed at C6, $\mathrm{C} 7, \mathrm{~T} 1$, and T2. The surgeon noted a very large acute epidural hematoma in the vicinity of $\mathrm{C} 7$ and T1 extending up to C6 and down to T3. The epidural hematoma was evacuated. Posterior instrumented



B. MRI Axial T1 imaging showing borders of epidural hematoma and mild compression of the cord.

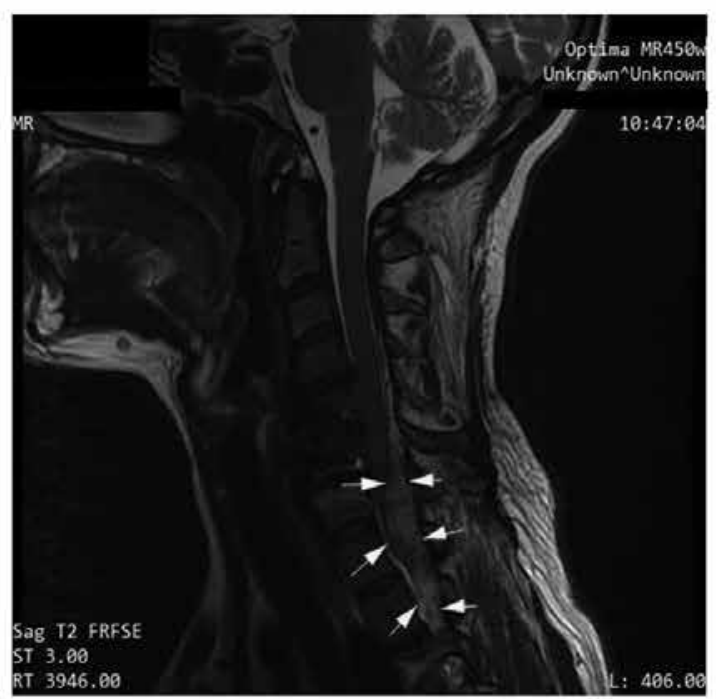

D. MRI Sagittal T2 imaging showing borders of epidural hematoma.

fusion was performed at C6, C7, T2, and T3 with autologous bone graft and allograft packed over the lateral masses and into the facet joints bilaterally. After the initial hospitalization of 3 days, she was discharged home satisfactorily.

She is being followed on an outpatient basis. She 


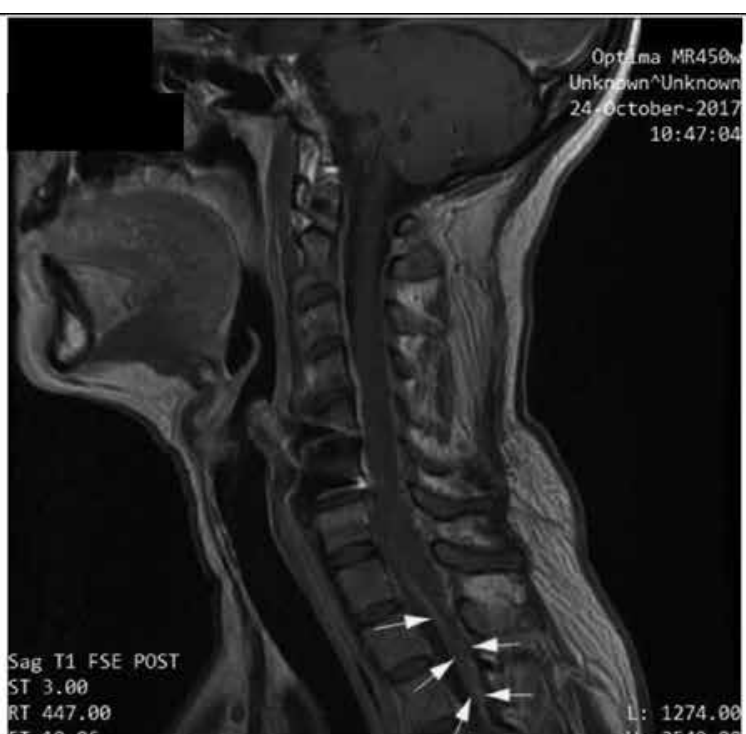

A. MRI Sagittal T1 imaging showing borders of epidural hematoma.

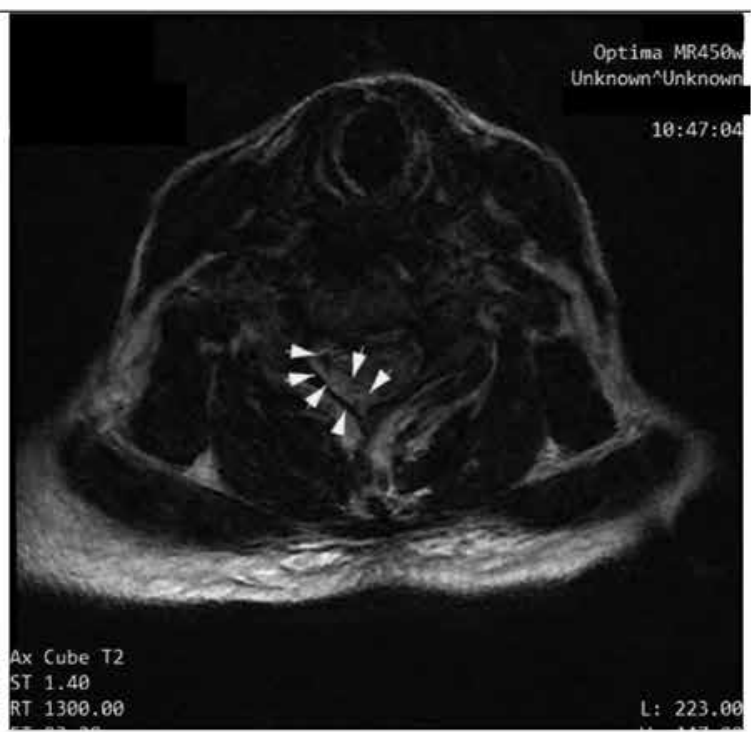

C. MRI Axial T2 cube imaging showing borders of epidural hematoma and deviation of cord to the left.

Fig. 3. MRI of epidural hematoma continued.

continues to have moderate neck pain, but she has returned to work and is functioning well. She has also developed a urinary tract infection on 2 occasions that was treated with antibiotics. There was no residual weakness or numbness.

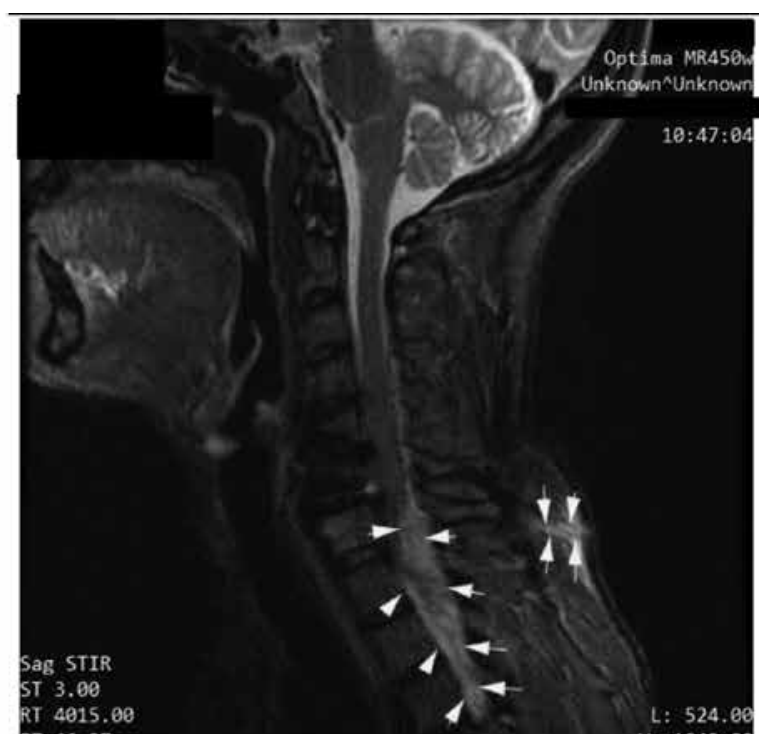

B. MRI Sagittal STIR imaging showing borders of epidural hematoma and tract of injection (far right)

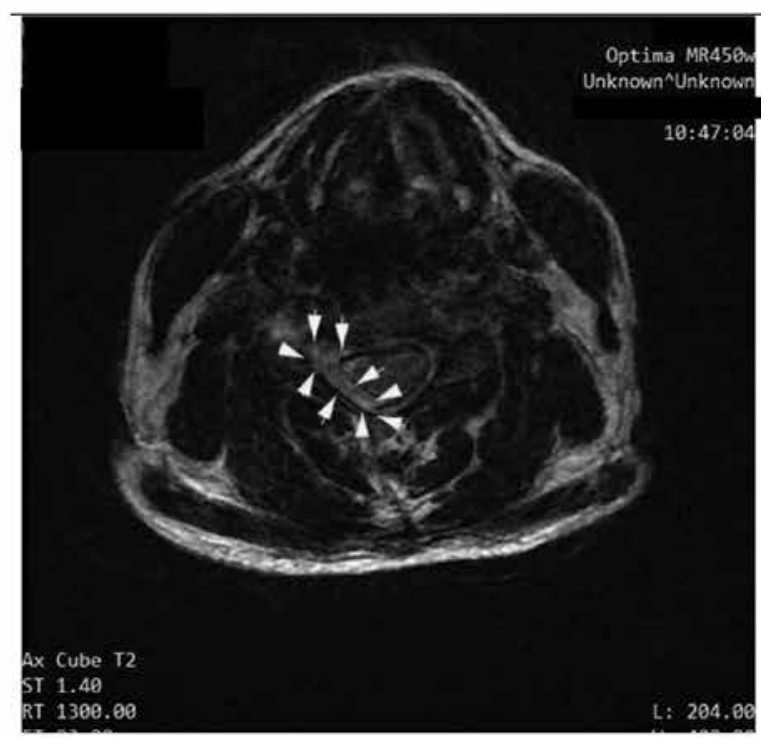

D MRI Axial T2 cube imaging showing borders of epidural hematoma and deviation of cord to the left.

\section{DISCUSSION}

This is a case of epidural hematoma with an uneventful, short, single attempt cervical epidural injection with a 5-second fluoroscopy, requiring surgi- 
cal decompression with complete recovery without residual sequelae, without antithrombotic therapy, SSRI therapy, fish oil, or any other drugs related to coagulopathy. However, she had an anterior cervical discectomy and fusion in the past, which may have presented a remote risk factor. This situation has been described as an intraoperative risk factor with increased bleeding from arteries in the posterior longitudinal ligament (20).

The literature has no prevalence statistics for cervical epidural hematoma, though a range of 1.38 in 10,000 to 1 in 250,000 epidural procedures has been reported (14). Even though Manchikanti et al $(15,16)$ have reported no instance of cervical epidural hematoma in patients taking anticoagulants, they have reported 2 cases of acute cervical epidural hematoma following a cervical epidural injections in 2 patients without active anticoagulant therapy (4). These 2 case reports provided a prevalence rate of $0.0085 \%$ ( 2 of 23,552 ) over a 16 -year period at their facility. The present case report adds to these numbers. Others have also reported cases in patients without antithrombotic therapy or associated bleeding risk $(5,7)$. However, there have been reports of cases related to antithrombotic therapy, fish oil, ketorolac, as well as SSRIs (1-3,6,20-25).

Cervical epidural hematoma is a rare complication of cervical epidural steroid injections. Anticoagulant therapy alone or with concomitant use of multiple drugs or supplements may increase the ultimate risk. An epidural hematoma may develop with or without anticoagulant therapy, and interlaminar entry into the epidural space has been categorized as high risk (1-3,19). Risk factors other than anterior cervical laminectomy and fusion include anatomic abnormalities of the vertebral column, technically difficult or repeated epidural procedures, older age, intrinsic thrombocytopenia, platelet dysfunction, renal failure, and coagulopathy related to hemophilia $(1-7,14,18)$. The majority of the cases reported in the literature are related to idiopathic or spontaneous origin with $17 \%$ being related to anticoagulation and only $10 \%$ related to spinal or epidural needle placement (26). In addition, the majority of the cases were also related to continuous epidurals in anticoagulated patients or in patients with thrombocytopenic disorders (27-29).
Consequently, single epidural injections are safer than continuous epidurals. Further, without technical difficulties and major anatomical risk factors, it is unusual to develop an epidural hematoma in a patient as in our case report. Anatomically, the cervical spinal cord is the most vulnerable to compression with defects in the dura because of the small diameter and small epidural space in this area compared to thoracic and lumbar levels (28). In addition to this, a wide anatomic variation has been reported with arterial distribution in the cervical spine, which may increase such risk with interlaminar epidural injections, but more commonly with transforaminal epidural injections (30).

In considering appropriate management of cervical epidural hematoma, conservative or surgical management may be offered. In general, large hematomas with rapid and debilitating onset of symptoms warrant urgent surgical decompression to avoid permanent deficits. Thus, conservative management is a recommendation for cervical epidural hematomas in patients presenting with minimal neural deficits and spontaneous recovery has been observed in these patients with minimal neurological deficits (4-7). Some individuals have recommended nonsurgical management with the postulation that it is $25 \%$ more effective than surgery in achieving complete recovery in spontaneous epidural hematoma, regardless of neural deficit upon presentation (31-34). However, in acute epidural hematoma following epidural injection, surgical management should always be considered as a priority in terms of decision making. Further, surgical management is always associated with inherent risks of nerve damage, leaks, and infections associated with multilevel laminectomies required to decompress often extensive hematomas (31). Based on current opinion and the case reports, it is recommended that ketorolac be avoided in interlaminar procedures in the post-operative period. Administration of ketorolac in the patient in this case report may have contributed to exacerbation of hematoma.

In summary, vigilance and appropriate therapy, including surgical intervention, is crucial in managing an acute epidural hematoma following an interlaminar epidural injection in patients with or without bleeding risks. 


\section{CONCLUSION}

Cervical interlaminar epidural injections are frequently used in managing chronic neck pain with local anesthetic alone or with steroids. Well-known causes of epidural hematoma include antithrombotic therapy, bleeding disorders, challenging placement/multiple attempts, and extensive anatomical anomalies. None of these were present in this patient. Rapid diagnosis and appropriate management with multidisciplinary decision making is crucial in achieving a successful and acceptable outcome.

\section{REFERENCES}

1. Manchikanti L, Falco FJE, Benyamin RM, Caraway DL, Kaye AD, Helm II S, Wargo BW, Hansen H, Parr AT, Singh V, Swicegood JR, Smith HS, Schultz DM, Malla Y, Hirsch JA. Assessment of bleeding risk of interventional techniques: $A$ best evidence synthesis of practice patterns and perioperative management of anticoagulant and antithrombotic therapy. Pain Physician 2013; 16:SE261-SE318.

2. Narouze S, Benzon HT, Provenzano D, Buvanendran A, De Andres J, Deer T, Rauck R, Huntoon MA. Interventional spine and pain procedures in patients on antiplatelet and anticoagulant medications (Second Edition): Guidelines from the American Society of Regional Anesthesia and Pain Medicine, the European Society of Regional Anaesthesia and Pain Therapy, the American Academy of Pain Medicine, the International Neuromodulation Society, the North American Neuromodulation Society, and the World Institute of Pain. Reg Anesth Pain Med 2018; 43:225-262.

3. Manchikanti L, Abdi S, Atluri S, Benyamin RM, Boswell MV, Buenaventura RM, Bryce DA, Burks PA, Caraway DL, Calodney AK, Cash KA, Christo PJ, Cohen SP, Colson J, Conn A, Cordner HJ, Coubarous S, Datta S, Deer TR, Diwan SA, Falco FJE, Fellows B, Geffert SC, Grider JS, Gupta S, Hameed H, Hameed M, Hansen $H$, Helm II S, Janata JW, Justiz R, Kaye AD, Lee M, Manchikanti KN, McManus CD, Onyewu O, Parr AT, Patel VB, Racz GB, Sehgal N, Sharma M, Simopoulos TT, Singh V, Smith HS, Snook LT, Swicegood J, Vallejo R, Ward SP, Wargo BW, Zhu J, Hirsch JA. An update of comprehensive evidence-based guidelines for interventional techniques of chronic spinal pain: Part II: Guidance and recommendations. Pain Physician 2013; 16:S49S283.

4. Manchikanti L, Malla Y, Benyamin RM, Hirsch JA. Prevalence of epidural hematoma following cervical epidural injections in interventional pain management settings: Literature review with two case reports. IPM Reports 2017; 1:11-17.

5. Swicegood J, Manchikanti L, Benyamin R, Hirsch J. Two cases of acute epidural hematoma formation after cervical interlaminar epidural steroid injections. IPM Reports 2017; 1:27-32.

6. Jenkie E, Benyamin R, Manchikanti L. Fish oil as a potential contributor to epidural hematoma following cervical epidural steroid injection: A case report and focused literature review. IPM Reports 2017; 1:19-26.
7. Benyamin RM, Vallejo R, Wang V, Kumar N, Cedeno DL, Tamrazi $A$. Acute epidural hematoma formation in cervical spine after interlaminar epidural steroid injection despite discontinuation of clopidogrel. Reg Anesth Pain Med 2016; 41:398-401.

8. Manchikanti L, Soin A, Mann DP, Bakshi S, Pampati V, Hirsch JA. Reversal of growth of utilization of interventional techniques in managing chronic pain in Medicare population post Affordable Care Act. Pain Physician 2017; 20:551-567.

9. Manchikanti L, Pampati V, Hirsch JA. Utilization of interventional techniques in managing chronic pain in Medicare population from 2000 to 2014: An analysis of patterns of utilization. Pain Physician 2016; 19:E531-E546.

10. Manchikanti L, Nampiaparampil DE, Candido KD, Bakshi S, Grider JS, Falco FJE, Sehgal N, Hirsch JA. Do cervical epidural injections provide long-term relief in neck and upper extremity pain? A systematic review. Pain Physician 2015; 18:39-60.

11. Manchikanti L, Nampiaparampil DE, Manchikanti KN, Falco FJE, Singh V, Benyamin RM, Kaye AD, Sehgal N, Soin A, Simopoulos TT, Bakshi S, Gharibo CG, Gilligan CJ, Hirsch JA. Comparison of the efficacy of saline, local anesthetics, and steroids in epidural and facet joint injections for the management of spinal pain: A systematic review of randomized controlled trials. Surg Neurol Int 2015; 6:S194-S235.

12. Manchikanti L, Pampati V, Hirsch JA. Retrospective cohort study of usage patterns of epidural injections for spinal pain in the US fee-for-service Medicare population from 2000 to 2014. BMJ Open 2016; 6:e013042.

13. Manchikanti L, Soin A, Mann DP, Bakshi S, Pampati V, Hirsch JA. Comparative analysis of utilization of epidural procedures in managing chronic pain in the medicare population: Pre and the post Affordable Care Act. 2018; in submission.

14. Chien GC, McCormick Z, Araujo M, Candido KD. The potential contributing effect of ketorolac and fluoxetine to a spinal epidural hematoma following a cervical interlaminar epidural steroid injection: A case report and narrative review. Pain Physician 2014; 17:E385-E395.

15. Manchikanti L, Malla Y, Wargo BW, Cash KA, McManus CD, Damron KS, Jackson SD, Pampati V, Fellows B. A prospective evaluation of bleeding risk of interventional techniques in chron- 
ic pain. Pain Physician 2011; 14:317-329.

16. Manchikanti L, Malla Y, Wargo BW, Cash KA, Pampati V, Fellows B. A prospective evaluation of complications of 10,000 fluoroscopically directed epidural injections. Pain Physician 2012; 15:131-140.

17. Endres S, Shufelt A, Bogduk N. The risks of continuing or discontinuing anticoagulants for patients undergoing common interventional pain procedures. Pain Med 2017; 18:403-409.

18. Manchikanti L, Benyamin RM, Swicegood JR, Falco FJE, Datta S, Pampati V, Fellows B, Hirsch JA. Assessment of practice patterns of perioperative management of antiplatelet and anticoagulant therapy in interventional pain management. Pain Physician 2012; 15:E955-E968.

19. Smith CC, Schneider B, McCormick ZL, Gill J, Loomba V, Engel AJ, Duszynski B, King W; Standards Division of the Spine Intervention Society. Risks and benefits of ceasing or continuing anticoagulant medication for image-guided procedures for spine pain: A systematic review. Pain Med 2018; 19:438-448.

20. U HS, Wilson CB. Postoperative epidural hematoma as a complication of anterior cervical discectomy. Report of three cases. J Neurosurg 1978; 49:288-291.

21. Yoo HS, Park SW, Han JH, Chung JY, Yi JW, Kang JM, Lee BJ, Kim DO. Paraplegia caused by an epidural hematoma in a patient with unrecognized chronic idiopathic thrombocytopenic purpura following an epidural steroid injection. Spine (Phila Pa 1976) 2009; 34:E376-E379.

22. Takahashi K, Koewa F, Tayama H, Satomi A, Akizawa T, Ideura T. A case of acute spontaneous epidural haematoma in a chronic renal failure patient undergoing haemodialysis: Successful outcomes with surgical management. Nephrol Dial Transplant 1999; 14:2499-2501.

23. Lim SH, Hong BY, Cho YR, Kim HS, Lee JI, Kim HW, Ko YJ. Relapsed spontaneous spinal epidural hematoma associated with aspirin and clopidogrel. Neurol Sci 2011; 32:687-689.

24. Novak V, Stefanović I, Kostić A, Radisavljević M, Novak M,
Jelenković B, Berilažić L. Cervical epidural hematoma: Case report. Srp Arh Celok Lek 2014; 142:589-591.

25. Perry A, Graffeo CS, Brinjikji W, Copeland WR 3rd, Rabinstein AA, Link MJ. Spontaneous occult intracranial hypotension precipitating life-threatening cerebral venous thrombosis: Case report. J Neurosurg Spine 2018; 28:669-678.

26. Kreppel D, Antoniadis G, Seeling W. Spinal hematoma: A literature survey with meta-analysis of 613 patients. Neuorsurg Rev 2003; 26:1-49.

27. Wulf H. Epidural anesthesia and spinal haematoma. Can J Anaesth 1996; 42:1260-1273.

28. Stoll A, Sanchez M. Epidural hematoma after epidural block: Implications for its use in pain management. Surg Neurol 2002; 57:235-240

29. Vandermeulen EP, Van Aken $\mathrm{H}$, Vermylen J. Anticoagulants and spinal-epidural anesthesia. Anesth Analg 1994; 79:1165-1177.

30. Huntoon MA. Anatomy of the cervical intervertebral foramina: Vulnerable arteries and ischemic neurologic injuries after transforaminal epidural injections. Pain 2005; 117:104-111.

31. Raasck K, Khoury J, Aoude A, Abduljabbar F, Jarzem P. Nonsurgical management of an extensive spontaneous spinal epidural hematoma causing quadriplegia and respiratory distress in a choledocholithiasis patient: A case report. Medicine (Baltimore) 2017; 96:e9368.

32. Groen RJ. Non-operative treatment of spontaneous spinal epidural hematomas: A review of the literature and a comparison with operative cases. Acta Neurochir (Wien) 2004; 146:103-110.

33. Raasck K, Habis AA, Aoude A, Simões L, Barros F, Reindl R, Jarzem P. Spontaneous spinal epidural hematoma management: A case series and literature review. Spinal Cord Ser Cases 2017; 3:16043.

34. Duffill J, Sparrow OC, Millar J, Barker CS. Can spontaneous spinal epidural haematoma be managed safely without operation? A report of four cases. J Neurol Neurosurg Psychiatry 2000; 69:816-819. 